\title{
Bacterias endofíticas aisladas de hojas y raíces de árboles de paraíso (Melia azedarach) con potencial actividad promotora del crecimiento vegetal
}

\author{
López Gastón,María M*; Fernández, Enzo; Cardozo, Marina C.; Collavino, Mónica M.
}

Instituto de Botánica del Nordeste, Facultad de Ciencias Agrarias (CONICET-UNNE)

*E-mail: yo_maura@ hotmail.com

Introducción. El paraíso (Melia azedarach L.), originario de la región del Himalaya, es un árbol muy cultivado en nuestro país. Su principal importancia radica en la multiplicidad de sus usos y en la calidad de su madera (Mangieriet al., 1977). La producción forestal de paraíso es afectada por una enfermedad causada por fitoplasmas, el declinamiento y amarillamiento. El objetivo del trabajo fue determinar actividades in vitro relacionadas con la promoción del crecimiento vegetal de bacterias endofíticas aisladas de hojas y raíces de árboles de paraíso.

Materiales y métodos. Se caracterizaron funcionalmente 65 aislamientos diferentes, representados por 26 géneros, pertenecientes principalmente los siguientes órdenes: Bacillales, Pseudomonadales, Enterobacteriales, Burkholderiales y Rhizobiales. Se seleccionó al menos un representante de cada género, excepto para los géneros Bacillus, Burkholderia, Kosakonia, Paenibacillus y Pseudomonas, en los cualesdebido a su reconocida actividad PGPR se evaluó al menos un representante de cada especie aislada. La producción de sideróforos se analizó por medición semicuantitativa con el método cromoazurol-S (CAS). Se midieron los diámetros de las colonias y de los halos generados, indicador de la secreción de sideróforos, y se calcularon los valores de actividad relativa (AR) según Pérez- Miranda, 2007. La disminución de los niveles de etileno en la planta (actividad 1- aminociclopropano-1carboxilato-ACC-deaminasa) se determinó cuantitativamente por espectrofotometría como una medida de producción de alfa- cetobutirato de acuerdo a Penrose and Glick, 2002. La producción de antibióticos: $p h l$ (2,4 diacetilfloroglucinol), prn (pirrolnitrina), plt (pioluteorina), phz (fenazina) encontrados en Pseudomonas; y zma (zwittermicina-A) encontrado en Bacillus, que se realizaron mediante la amplificación de genes por PCR utilizando los siguientes cebadores: B2BF1-BPR4 para el gen phl, prnC1-prnC3 para el gen prn, plt1 y plt2 para el gen plt y Ps_up1-Ps_low1 para el gen phz y A0677A0678 para el gen zma.

Resultados. En más de la mitad de los aislamientos (38) se evidenció la producción de sideróforos, 12 de estas cepas pertenecientes a los géneros Burkholderia, Pseudomonas y Variovorax presentaron valores de actividad significativamente mayores a los observados en la cepa control (Pseudomona putida). Uno de estos aislamientos pertenecientes al género Pseudomonas fue además caracterizado por ser altamente eficiente en la solubilización de P, fijador de $\mathrm{N}$ y productor de AIA. En contraste, los aislamientos pertenecientes al género Kosakonia resultaron poco productores de sideróforos.

La actividad ACC deaminasa se evidenció en 16 de los aislamientos. En 5 de los mismos, pertenecientes a los géneros Burkholderia, Cupriavidus, Ralstonia y Variovorax, se observaron niveles de producción mayor a los producidos por la cepa de referencia (Pseudomona putida).

Quince de los 23 aislamientos seleccionados de Pseudomonas mostraron amplificación para alguno de los genes relacionados con la actividad de antibiosis. En 4 aislamientos se amplificó el gen phl, en 6 el gen prn, en 4 el gen phz y en 1 el gen plt. En contraste, solo un aislamiento del género Bacillus mostró amplificación del gen zma relacionado con la producción de zwitermicina.

Conclusión. Encontramos que la mayoría de los aislamientos endofíticos de paraíso presenta componentes con alta eficiencia en las actividades promotoras del crecimiento vegetal analizadas, con valores que en algunos casos duplican los observados en las cepas de referencia.

Referencias bibliográficas.

Mangieri, H.R.; Tinto, J.C.; Leonardis, R.J.; Alonzo, A.; Reuter, H.R. En: Libro del Árbol. Celulosa Argentina (ed.) Buenos Aires. Tomo III: 62, 1977.

Penrose,D.M. andGlick, B.R. Methods of isolating and characterizing ACC deaminase-containing plant growth -promoting rhizobacteria. Physiologia plantarum 118: 10-15, 2003.

Pérez- Miranda, S.; Cabirol, N.; George- Téllez, R.; Zamudio-Rivera, L.S.; Fernández, F.J. O-CAS, a fast and universal method for siderophore detection. Journal of Microbiological Methods 70: 127- 131, 2007. 